\title{
Evaluation of a Trapezoidal Predictive Controller for a Four-Wire Active Power Filter for Utility Equipment of Metro Railway, Power-Land Substations
}

\author{
Sergio Salas-Duarte, ${ }^{1}$ Ismael Araujo-Vargas, ${ }^{1}$ \\ Jazmin Ramirez-Hernandez, ${ }^{1}$ and Marco Rivera ${ }^{2}$ \\ ${ }^{1}$ Escuela Superior de Ingeniería Mecanica y Eléctrica, Unidad Culhuacan, Instituto Politécnico Nacional, Avenida Santa Ana No. 1000, \\ Col San Francisco Culhuacan, 04430 México, DF, Mexico \\ ${ }^{2}$ Universidad de Talca, 2 Norte 685, Talca, Chile \\ Correspondence should be addressed to Ismael Araujo-Vargas; iaraujo@ipn.mx
}

Received 14 August 2015; Accepted 20 December 2015

Academic Editor: Shengbo Eben Li

Copyright @ 2016 Sergio Salas-Duarte et al. This is an open access article distributed under the Creative Commons Attribution License, which permits unrestricted use, distribution, and reproduction in any medium, provided the original work is properly cited.

The realization of an improved predictive current controller based on a trapezoidal model is described, and the impact of this technique is assessed on the performance of a $2 \mathrm{~kW}, 21.6 \mathrm{kHz}$, four-wire, Active Power Filter for utility equipment of Metro Railway, Power-Land Substations. The operation of the trapezoidal predictive current controller is contrasted with that of a typical predictive control technique, based on a single Euler approximation, which has demonstrated generation of high-quality line currents, each using a $400 \mathrm{~V}$ DC link to improve the power quality of an unbalanced nonlinear load of Metro Railway. The results show that the supply current waveforms become virtually sinusoidal waves, reducing the current ripple by $50 \%$ and improving its power factor from 0.8 to 0.989 when the active filter is operated with a $1.6 \mathrm{~kW}$ load. The principle of operation of the trapezoidal predictive controller is analysed together with a description of its practical development, showing experimental results obtained with a $2 \mathrm{~kW}$ prototype.

\section{Introduction}

The use of Active Power Filters (APFs) in the electrical grid is critical for on-land transportation applications, such as Metropolitan Railway Substations, which reduce the flowing of current harmonics caused by the increased utilization of nonlinear loads, whilst improving the power quality of the supply. APFs are an attractive solution to comply with the national and international power quality standards at every level of the network infrastructure, [1-3], since highperformance switching devices appear available in the market to develop power converters [4]. In addition, the development of fast and versatile microprocessors has facilitated the implementation of nonlinear control techniques, and thereby, APFs are becoming accurate power processors that reshape clean sinusoidal supply currents [5-9].
Four-wire shunt APFs are a commonplace strategy that exhibit attractive characteristics to inject currents and reshape the line currents drawn by unbalanced nonlinear loads, whilst providing a path to cancel the neutral current by using either an additional switching limb or a split DC link $[10,11]$. These circuits typically incur in the use of a power theory to calculate the reference currents [12], such that the filter may operate as a current amplifier that injects compensating currents to the grid, causing a complex transistor switching scheme since the generated filter currents must track the references. Predictive control is an attractive method for controlling current waveforms in three-phase converters $[6,7$, 13-20], since a piecewise linear model of the converter is used together with a cost function to determine an appropriate converter switching. 


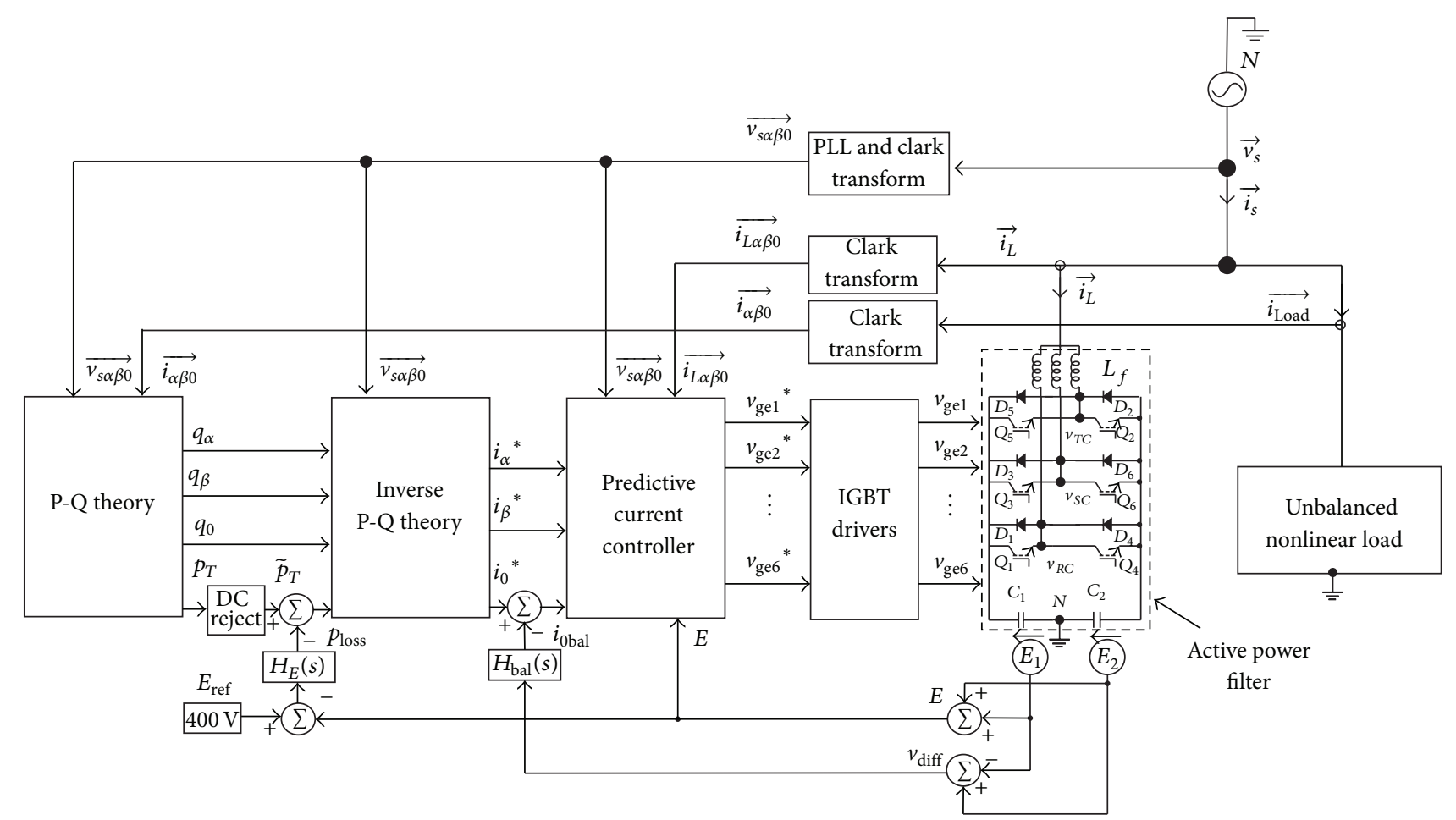

FIGURE 1: Four-wire shunt active filter and its corresponding control block diagram.

This paper presents the realization and experimental verification of a trapezoidal predictive current controller for a four-wire shunt APF that improves the power quality of unbalanced AC loads in contrast to the typical predictive Euler control strategy. The trapezoidal strategy relies its operation on a discrete trapezoidal linear approximation that more accurately determines the switching of the active filter for the one-step ahead current sample, such that three significant advantages are potentially exhibited: first, the trapezoidal predictive controller slightly increments the processing time without affecting the switching of the power converter; second, in contrast to the typical Euler approximation used in other works $[6,7,13-20]$, the trapezoidal method generates lower AC current ripple; and third, the convergence time and load operating performance are wider than those obtained using the typical predictive control strategy, which improves the reference current tracking and, therefore, the power quality. Experimental results obtained with a $2 \mathrm{kVA}$ prototype are presented, demonstrating that the trapezoidal predictive control may accurately compensate the currents drawn by an unbalanced nonlinear load under static and dynamic conditions.

\section{Four-Wire Shunt Active Filter}

2.1. Circuit Description. The four-wire shunt APF is connected in parallel to the unbalanced nonlinear load as shown at the right-hand side of Figure 1, which consists of a split DC link formed by $C_{1}$ and $C_{2}$ which refer to the AC supply neutral node $N$ to provide a path to mitigate a common mode current: a typical three-phase, current-feed active converter, formed by transistors $Q_{1}$ to $Q_{6}$ and diodes $D_{1}-D_{6}$, and three line filter inductors $L_{f}$ used to generate the filter current vector, $\overrightarrow{i_{L}}=\left[\begin{array}{lll}i_{L R} & i_{L S} & i_{L T}\end{array}\right]^{T}$, by the difference between the supply and converter voltage vectors $\vec{v}_{s}=\left[\begin{array}{lll}v_{R N} & v_{S N} & v_{T N}\end{array}\right]^{T}$ and $\overrightarrow{v_{C}}=\left[\begin{array}{lll}v_{R C N} & v_{S C N} & v_{T C N}\end{array}\right]^{T}$, thereby obtaining virtual sinusoidal supply currents $\overrightarrow{i_{s}}=\left[\begin{array}{lll}i_{S R} & i_{S S} & i_{S T}\end{array}\right]^{T}$.

2.2. Principle of Operation of the Active Filter. The principle of operation of the APF of Figure 1 may be described using the control block diagram presented at the left-hand side of Figure 1. An instantaneous active and reactive power theory, P-Q theory block in Figure 1 [12], is used to obtain an effective calculation of the reference currents that the APF may inject to the supply to instantaneously mitigate the reactive and distorted power components, drawn by the nonlinear load, and balance the active power per phase. The $\mathrm{P}-\mathrm{Q}$ theory uses the Clarke transformation of the supply voltage and load current as shown in

$$
v_{\alpha \beta \theta}=\left[\begin{array}{c}
v_{0} \\
v_{\alpha} \\
v_{\beta}
\end{array}\right]=\sqrt{\frac{2}{3}}\left[\begin{array}{ccc}
\frac{1}{\sqrt{2}} & \frac{1}{\sqrt{2}} & \frac{1}{\sqrt{2}} \\
1 & -\frac{1}{2} & -\frac{1}{2} \\
0 & \frac{\sqrt{3}}{2} & -\frac{\sqrt{3}}{2}
\end{array}\right]\left[\begin{array}{c}
v_{R N} \\
v_{S N} \\
v_{T N}
\end{array}\right],
$$




$$
i_{\alpha \beta \theta}=\left[\begin{array}{l}
i_{0} \\
i_{\alpha} \\
i_{\beta}
\end{array}\right]=\sqrt{\frac{2}{3}}\left[\begin{array}{ccc}
\frac{1}{\sqrt{2}} & \frac{1}{\sqrt{2}} & \frac{1}{\sqrt{2}} \\
1 & -\frac{1}{2} & -\frac{1}{2} \\
0 & \frac{\sqrt{3}}{2} & -\frac{\sqrt{3}}{2}
\end{array}\right]\left[\begin{array}{l}
i_{\text {Load } R} \\
i_{\text {LoadS }} \\
i_{\text {LoadT } T}
\end{array}\right]
$$

such that the calculation of the active and reactive instantaneous powers in the $\alpha \beta 0$ coordinate system is obtained as, respectively, shown in

$$
\begin{aligned}
& p_{T}=\overrightarrow{v_{\alpha \beta 0}} \cdot \overrightarrow{i_{\alpha \beta 0}}=v_{\alpha} i_{\alpha}+v_{\beta} i_{\beta}+v_{0} i_{0}, \\
& q=\overrightarrow{v_{\alpha \beta 0}} \times \overrightarrow{i_{\alpha \beta 0}}=\left[\begin{array}{l}
q_{\alpha} \\
q_{\beta} \\
q_{\theta}
\end{array}\right]=\left[\begin{array}{ll}
{\left[\begin{array}{ll}
v_{\beta} & v_{0} \\
i_{\beta} & i_{0}
\end{array}\right]} \\
{\left[\begin{array}{ll}
v_{\theta} & v_{\alpha} \\
i_{0} & i_{\alpha}
\end{array}\right]} \\
{\left[\begin{array}{ll}
v_{\alpha} & v_{\beta} \\
i_{\alpha} & i_{\beta}
\end{array}\right]}
\end{array}\right],
\end{aligned}
$$

where $p_{T}$ is the real power or internal product of the voltage and current vectors and $q$ is the imaginary vector power or external product of the voltage and current vectors which is composed of $q_{\alpha}, q_{\beta}$, and $q_{0}$. Since the load uses a fourth conductor, namely, the neutral, which is very common in lowvoltage distribution system, the P-Q calculation may include both zero-sequence voltage and current as shown in (2) and (3). Therefore, the instantaneous powers defined above may be combined in a single matrix transformation as shown as follows:

$$
\left[\begin{array}{l}
p_{T} \\
q_{\alpha} \\
q_{\beta} \\
q_{0}
\end{array}\right]=\left[\begin{array}{ccc}
v_{\alpha} & v_{\beta} & v_{0} \\
0 & -v_{0} & v_{\beta} \\
v_{0} & 0 & -v_{\alpha} \\
-v_{\beta} & v_{\alpha} & 0
\end{array}\right]\left[\begin{array}{l}
i_{\alpha} \\
i_{\beta} \\
i_{0}
\end{array}\right]
$$

which is defined on the $\alpha \beta 0$ reference frame. $p_{T}$ and $q$ are instantaneous power signals that have averaged and oscillatory components that may be used to calculate a reference current vector for the APF control system. The average of $p_{T}$, $\bar{p}$, corresponds to the energy per time unity that is transferred from the supply to the load and becomes the power that the system truly uses [8]. In this way, the ideal condition would be to remove the oscillatory portion of the real power $p$ and the imaginary power $q$ of power drawn by the load, such that the calculation of the reference currents for compensating the currents drawn by the load may be given with

$$
\left[\begin{array}{l}
i_{\alpha \mathrm{ref}}{ }^{*} \\
i_{\beta \mathrm{ref}}{ }^{*} \\
i_{0 \mathrm{ref}}{ }^{*}
\end{array}\right]=\frac{1}{v_{\alpha \beta \theta}^{2}}\left[\begin{array}{cccc}
v_{\alpha} & 0 & v_{\theta} & -v_{\beta} \\
v_{\beta} & -v_{\theta} & 0 & v_{\alpha} \\
v_{\theta} & v_{\beta} & -v_{\alpha} & 0
\end{array}\right]\left[\begin{array}{c}
\widetilde{p} \\
q_{\alpha}{ }^{*} \\
q_{\beta}{ }^{*} \\
q_{0}{ }^{*}
\end{array}\right]
$$

which is represented in Figure 1 as the inverse P-Q theory block, which subtracts $\bar{p}$ from $p$ to obtain the oscillatory component of $p, \widetilde{p}$. In this fashion, the reference currents of (5) are used to operate the three-phase converter of Figure 1 as a current amplifier driven by the trapezoidal predictive current controller block shown at the centre of Figure 1.

2.3. DC-Link Voltage Controller. The APF requires a fixed DC-link capacitor voltage $E$ greater than the peak value of the line-to-line supply voltage, for instance, $E=400 \mathrm{~V}$ when a $220 \mathrm{~V}, 60 \mathrm{~Hz}$ supply is being used. Since the shunt APF topology is identical to that of an active three-phase rectifier [14], the circuit boosts the DC-link voltage using an external voltage control loop that generates a loss power control signal, $p_{\text {loss }}$, which is added to $\widetilde{p}$ to supply energy for the DC-link capacitor and compensate the power losses of the APF circuit. This is shown in the left bottom side of Figure 1, where a linear control loop calculates $p_{\text {loss }}$ using the error between the $E$ reference, $E_{\text {ref }}$, and the DC-link voltage $E$, which is obtained adding the measured DC-link capacitor voltages, and compensating this error with $H_{E}(s)$.

2.4. DC-Link Capacitor Voltage Balancing Controller. Since the split DC-link node $N$ is used to draw a compensating current for the neutral wire of the supply, the DC-link capacitor voltages may become unbalanced due to the flow of a small DC current. An additional zero-sequence, balancing current, $i_{0 \text { bal }}$, is used after the zero-sequence reference current calculation to overcome a voltage unbalance between the capacitors of the split DC link [21]. This is shown at the bottom of Figure 1, where again a linear control loop calculates $i_{0 \text { bal }}$ by compensating the error between the DC-link capacitor voltages, $v_{\text {dif }}$, with $H_{\text {bal }}(s)$.

\section{Trapezoidal Predictive Current Controller}

3.1. Discrete Linear Model of the APF Converter. A space vector AC-side model of the APF three-phase converter is derived calculating the filter inductor voltage vector as shown in

$$
\overrightarrow{v_{L \alpha \beta 0}}=L \frac{d \overrightarrow{i_{L \alpha \beta 0}}}{d_{t}}=\overrightarrow{v_{s \alpha \beta 0}}-\overrightarrow{v_{c \alpha \beta 0}}
$$

which may be solved to calculate the line current vector $\overrightarrow{i_{L}}$ as shown as follows:

$$
\overrightarrow{i_{L \alpha \beta 0}}\left(t_{1}\right)=\overrightarrow{i_{L \alpha \beta 0}}\left(t_{1}+k T\right)+\int_{t_{1}+k T}^{t_{1}+(k+1) T} \overrightarrow{v_{L \alpha \beta 0}}(t) d t .
$$

A discrete time model of (7) may be obtained by using the trapezoidal approximation shown in Figure 2, such that (7) becomes

$$
\begin{aligned}
& {\overrightarrow{i_{L \alpha \beta 0} 0_{k+1}}}{\overrightarrow{i_{L \alpha \beta 0}}}^{\longrightarrow} \\
& \quad+\frac{T_{s}}{2 L}\left[{\overrightarrow{v_{s \alpha \beta 0}}}_{k}-{\overrightarrow{v_{c \alpha \beta 0}}}_{k}+{\overrightarrow{v_{s \alpha \beta 0}}}_{k+1}-{\overrightarrow{v_{c \alpha \beta 0}}}_{k+1}\right],
\end{aligned}
$$




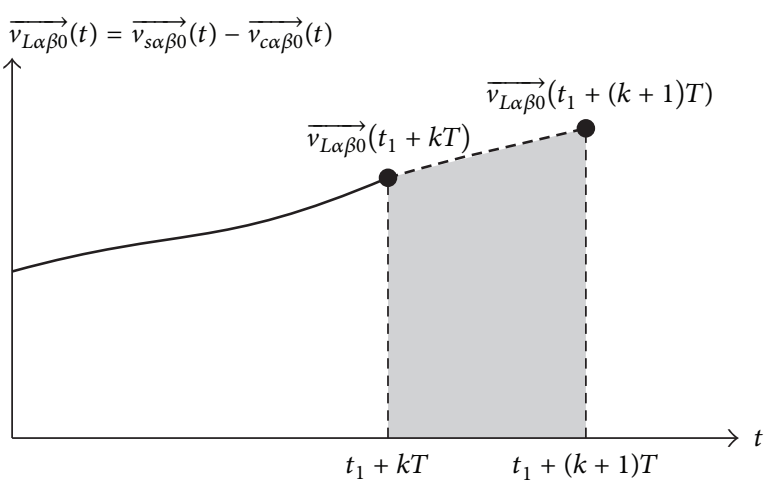

FIGURE 2: Trapezoidal approximation of the volt-seconds integral of (9).

where $T$ is the sampling period that must be small to obtain an accurate model approximation of the system. Since ${\overrightarrow{v_{s \alpha \beta 0}}}_{k} \approx$

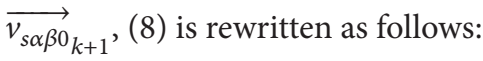

$$
{\overrightarrow{i_{L \alpha \beta 0}}}_{k+1} \cong{\overrightarrow{i_{L \alpha \beta 0}}}_{k}+\frac{T_{s}}{2 L}\left[2{\overrightarrow{v_{s \alpha \beta 0}}}_{k}-{\overrightarrow{v_{c \alpha \beta 0}}}_{k}-{\overrightarrow{v_{c \alpha \beta 0}}}_{k+1}\right]
$$

which may produce eight one-step ahead current vectors, ${\overrightarrow{i_{L \alpha \beta 0} 0_{k+1}}}^{0}$ to ${\overrightarrow{i_{L \alpha \beta 0}}}_{k+1}^{7}$, since ${\overrightarrow{v_{c \alpha \beta 0}}}_{k+1}$ has six active, ${\overrightarrow{v_{c \alpha \beta 0}}}^{1}$ to ${\overrightarrow{v_{c \alpha \beta 0}}}^{6}$, and two neutral vectors, ${\overrightarrow{v_{c \alpha \beta 0}}}^{0}$ and ${\overrightarrow{v_{c \alpha \beta 0}}}^{7}$, that are listed in Table 1 with respect to their transistor switching states, assuming the common mode voltage due to the AC neutral node connection to the DC link [15]. $\overrightarrow{i_{L \alpha \beta 0}}{ }_{k+1}^{0}$ to ${\overrightarrow{i_{L \alpha \beta 0}}}_{k+1}^{7}$ are dispersed around the $k$ th current sample, $\vec{i}_{L \alpha \beta 0_{k}}$, as shown in $\alpha \beta 0$ frame of Figure 3, such that one of these may become near to the reference current sample ${\overrightarrow{i_{L \alpha \beta 0} 0_{k}}}^{*}$.

\subsection{Cost Function of the Current Controller. An error current} vector, $\overrightarrow{i_{L e \alpha \beta 0_{k}}}$, may be used as a cost function to evaluate which of the transistor switching states causes the nearest one-step ahead current sample to ${\overrightarrow{i_{L \alpha \beta 0_{k}}}}^{*}$, such that $\overrightarrow{i_{L e \alpha \beta 0_{k}}}$ may be expressed as shown as follows [16]:

$$
{\overrightarrow{i_{L e \alpha \beta 0_{k}}}}^{0-7}={\overrightarrow{i_{L \alpha \beta 0_{k}}}}^{*}-{\overrightarrow{i_{L \alpha \beta 0}}}_{k+1}^{0-7} \text {. }
$$

The size of (10) may be evaluated using the Euclidean norm of ${\overrightarrow{i_{L e \alpha \beta 0_{k}}}}^{0-7},\left\|{\overrightarrow{i_{L e \alpha \beta 0_{k}}}}_{0^{-7}}\right\|^{2}$, which is equal to

$$
\begin{aligned}
\left\|\vec{i}_{L e \alpha \beta 0_{k}}{ }^{0-7}\right\|^{2}= & \left|i_{L \alpha k}^{*}-i_{L \alpha k+1}^{0-7}\right|^{2}+\left|i_{L \beta_{k}}^{*}-i_{L \beta_{k+1}}^{0-7}\right|^{2} \\
& +\left|i_{L 0 k}^{*}-i_{L 0 k+1}^{0-7}\right|^{2}
\end{aligned}
$$

such that the minimum $\left\|{\overrightarrow{i_{L e \alpha \beta 0_{k}}}}^{0-7}\right\|^{2}$ determines the transistor switching state that may be used at the $k$ th instant to produce an appropriate three-phase, filter current tracking with respect to the current reference vector [17].
3.3. Control Algorithm of the Four-Wire APF. Following the description given above, a flow diagram of the APF control algorithm of Figure 1 is shown in Figure 4. This diagram starts with the parameters initialization of the microcontroller and then enters to an iterative loop control cycle. In this cycle, all the voltage and currents variables are sensed, such as the supply voltage $\overrightarrow{v_{s}}$, the filter current, $\overrightarrow{i_{L}}$, the load current, $\vec{i}_{\text {Load }}$, and the DC-link voltage, $E$, where the AC inputs are converted to $\alpha \beta 0$ plane using (1). Since the APF may operate with a distorted voltage, or high source impedance [22], $\vec{v}_{s}$ is processed with a Phase Locked Loop (PLL) to obtain a clean three-phase supply and phase reference. The next process in the algorithm is the calculation of the two external voltage controllers used to maintain charged and balanced DC-link capacitors at a fixed voltage level, which contribute to calculate the reference currents through the inverse P-Q theory, (4) and (5). Once the reference currents are calculated, an "else-if" tree is started to process the trapezoidal predictive current controller with the eight possible transistor state combinations of the APF converter, which uses the discrete current model of (7) and the cost function of (10), such that eight one-step ahead current values are evaluated and then weighted against the current reference vector using (10). Finally, the converter state vector that minimizes the cost function is determined and, thereby, the algorithm applies the selected state vector to the APF converter.

\section{Experimental Verification}

4.1. Prototype Description. A $2 \mathrm{kVA}$, four-wire shunt APF prototype rig was built to evaluate the operation of the APF of Figure 1. Table 2 lists the operating parameters and components of the rig.

A $150 \mathrm{MHz}$ TMS320F28335 Digital Signal Processor (DSP) was used to implement the control strategy of Figures 1 and 4 using a 32-bit data word length for floating point operations ensuring numerical stability. Additional hardware was utilized to interface the DSP with the power converter, such as voltage and current sensors, signal conditioners, IGBT drivers, and fiber optic links. The APF was operated with the aid of a PLL [22] and driven with either the trapezoidal predictive controller (9) or a typical predictive controller that uses the Euler approximation of

$$
{\overrightarrow{i_{L \alpha \beta 0}}}_{k+1} \cong{\overrightarrow{i_{L \alpha \beta 0}}}_{k}+\frac{T_{s}}{L}\left[{\overrightarrow{v_{s \alpha \beta 0}}}_{k}-{\overrightarrow{v_{c \alpha \beta 0}}}_{k+1}\right]
$$

to experimentally compare the performance.

4.2. Experimental Results. The $2 \mathrm{kVA}$ APF prototype was verified with the Euler and trapezoidal predictive current controllers and a $127 \mathrm{~V}, 60 \mathrm{~Hz}$ line-to-neutral supply voltage and under three nonlinear load conditions: a $1.6 \mathrm{~kW}$, naturally controlled three-phase rectifier with a $L C$ filter, Figure 5(a); a $0.9 \mathrm{~kW}$, four-wire unbalanced load, Figure 5(b), that consisted of two naturally controlled single-phase rectifiers, both with a $L C$ output filter and each supplied with different single phases, and a resistive load supplied with a single phase; and a $1 \mathrm{~kW}$ unbalanced load condition, Figure 5(c), similar to 
TABLE 1: Normalized converter voltage space vectors with respect to the transistor switching states.

\begin{tabular}{|c|c|c|c|c|c|c|c|c|c|}
\hline \multicolumn{6}{|c|}{ Transistor state combination } & \multirow{2}{*}{$\overrightarrow{v_{c \alpha \beta 0}}$} & \multicolumn{3}{|c|}{ Normalized converter voltages } \\
\hline$Q_{1}$ & $Q_{2}$ & $Q_{3}$ & $Q_{4}$ & $Q_{5}$ & $Q_{6}$ & & $V_{\alpha} / E$ & $V_{\beta} / E$ & $V_{0} / E$ \\
\hline 0 & 1 & 0 & 1 & 0 & 1 & ${\overrightarrow{v_{c \alpha \beta 0}}}^{0}$ & 0 & 0 & $-\frac{1}{2}$ \\
\hline 1 & 1 & 0 & 0 & 0 & 1 & ${\overrightarrow{v_{c \alpha \beta 0}}}^{1}$ & $\sqrt{\frac{2}{3}}$ & 0 & $-\frac{1}{6}$ \\
\hline 1 & 1 & 1 & 0 & 0 & 0 & ${\overrightarrow{v_{c \alpha \beta 0}}}^{2}$ & $\frac{\sqrt{6}}{6}$ & $\frac{1}{\sqrt{2}}$ & $\frac{1}{6}$ \\
\hline 0 & 1 & 1 & 1 & 0 & 0 & ${\overrightarrow{v_{c \alpha \beta 0}}}^{3}$ & $-\frac{\sqrt{6}}{6}$ & $\frac{1}{\sqrt{2}}$ & $-\frac{1}{6}$ \\
\hline 0 & 0 & 1 & 1 & 1 & 0 & ${\overrightarrow{v_{c \alpha \beta 0}}}^{4}$ & $-\sqrt{\frac{2}{3}}$ & 0 & $\frac{1}{6}$ \\
\hline 0 & 0 & 0 & 1 & 1 & 1 & ${\overrightarrow{v_{c \alpha \beta 0}}}^{5}$ & $-\frac{\sqrt{6}}{6}$ & $-\frac{1}{\sqrt{2}}$ & $-\frac{1}{6}$ \\
\hline 1 & 0 & 0 & 0 & 1 & 1 & ${\overrightarrow{v_{c \alpha \beta 0}}}^{6}$ & $\frac{\sqrt{6}}{6}$ & $-\frac{1}{\sqrt{2}}$ & $\frac{1}{6}$ \\
\hline 1 & 0 & 1 & 0 & 1 & 0 & ${\overrightarrow{v_{c \alpha \beta 0}}}^{7}$ & 0 & 0 & $\frac{1}{2}$ \\
\hline
\end{tabular}

TABLE 2: Operating parameters and components of the four-wire APF prototype.

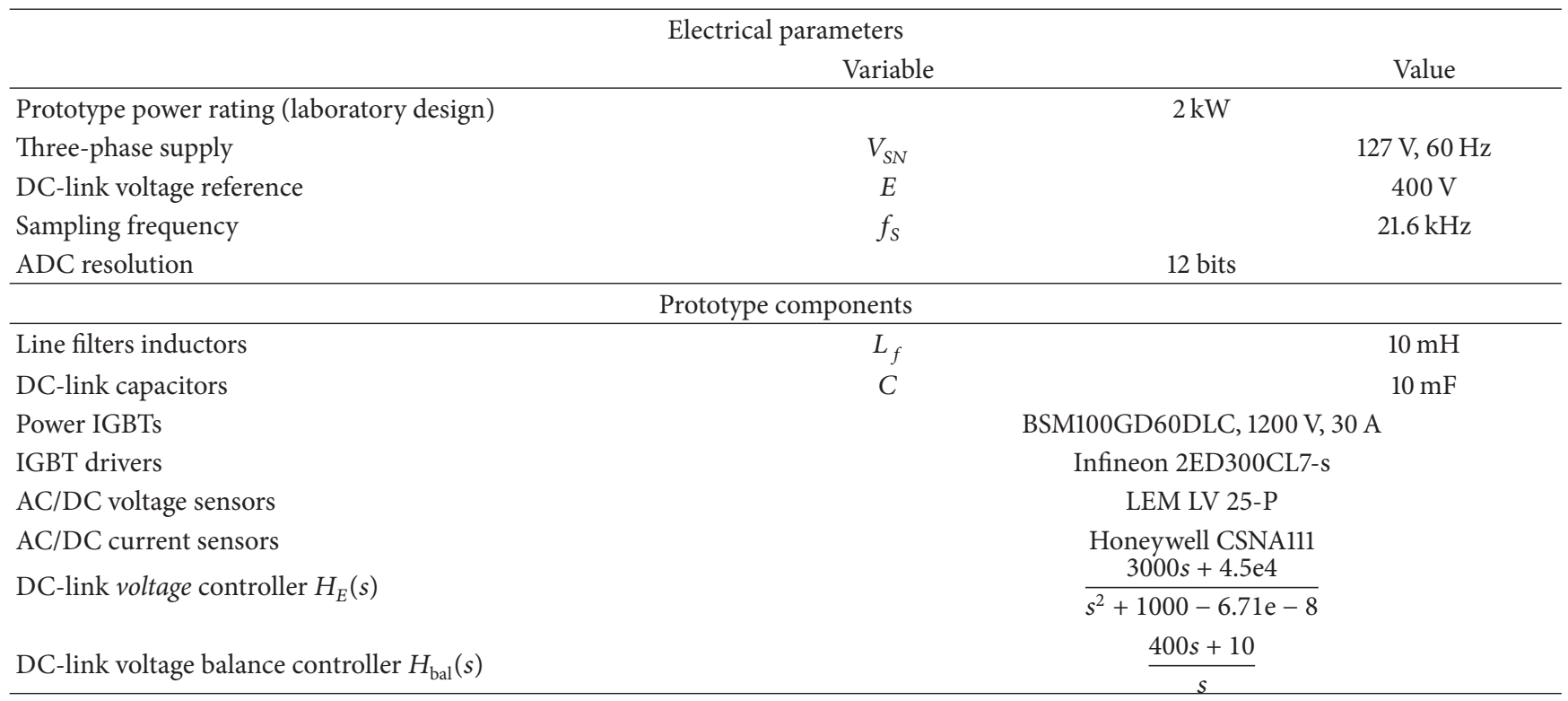

the one used at a power substation of Line B, Metropolitan Railway of Mexico City, for powering electronic utility equipment.

Figure 6(a) shows the experimental supply currents $i_{S R}$, $i_{S S}$, and $i_{S T}$ and one supply phase voltage, $v_{R N}$, obtained with the load condition of Figure 6(a). The experimental line current waveforms were typical of a three-phase, 6-pulse rectifier without the operation of the APF, but, when the APF was turned on using the Euler predictive controller, the supply currents became virtually sinusoidal waveforms, with the supply currents Total Harmonic Distortion (THD) and the total power factor being improved from $29 \%$ to $15 \%$ and from 0.95 to 0.98 , respectively, which confirmed that the APF was properly operating. Two main characteristics were found in the experimental supply current waveforms of Figure 6(a): a $4.2 \mathrm{kHz}$, high-frequency ripple and a small glitch occurring at every rising and falling slope of the load current waveform.
The first was attributed to the Euler approximation used with the predictive control switching that continuously tracks the reference currents [23], which was confirmed with a dynamic condition of stepping the output filter inductance from $50 \mathrm{mH}$ to $100 \mathrm{mH}$. Figure 6(b) shows that the operation of the APF with the Euler predictive current control and the P$\mathrm{Q}$ theory is maintained throughout the filter inductance step, since the sinusoidal waveform quality of the supply currents is stable as shown in Figure 6(b), ensuring reliable operation of the APF and, therefore, the predictive controller is likely to be compliant under dynamic conditions, a typical requirement for control techniques; however, the amplitude of the filter current waveforms slightly fell from $2 \mathrm{~A}$ to $1.5 \mathrm{~A}$ during the transient response, with the supply current THD being barely degraded around $24 \%$. The second characteristic was confirmed by contrasting the measured filter current $i_{L R}$ with its digital reference $i_{L R}{ }^{*}$, as shown in the left-hand side 


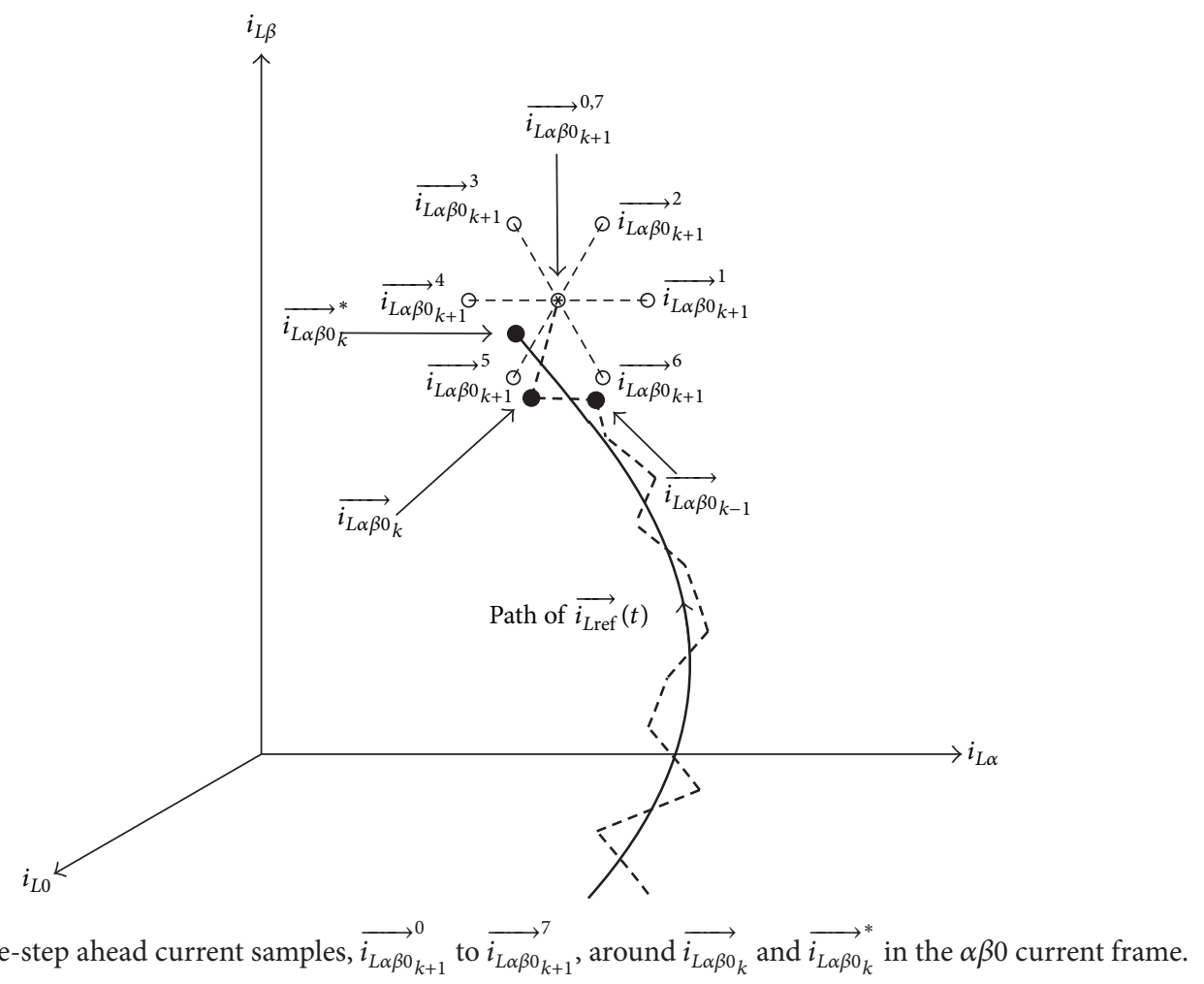

of Figure 6(c), revealing that the predictive current control slightly follows the reference during the high $d i / d t$ periods of the load current waveforms due to the simple Euler approximation used in the algorithm, reducing the tracking accuracy of the references, and, therefore, introducing small glitches to the supply current waveforms. This undesired phenomenon was improved by changing the Euler approximation of the predictive controller to the trapezoidal technique as shown in the right-hand side of Figure 6(c), which reveals in its amplification shown in Figure 6(d) that the trapezoidal predictive controller reduces the current ripple amplitude by approximately 50\%, increasing its frequency rate from $4.2 \mathrm{kHz}$ to $9.5 \mathrm{kHz}$ and producing a lower supply current THD, $10.2 \%$, and a power factor of 0.989 in contrast to the Euler technique, with the supply current waveforms becoming virtually free of high-frequency glitches and ripple.

Figure 7 (a) shows the experimental supply currents $i_{S R}$, $i_{S S}$, and $i_{S T}$ and the neutral current $i_{N}$ obtained with the unbalanced load condition of Figure 5(b) at $0.9 \mathrm{~kW}$. This figure shows that the line currents are typical of an unbalanced nonlinear load before the APF is activated, and, after the APF is on, the supply currents become virtually balanced sinusoidal waveforms of $2.4 \mathrm{~A}$, with the supply current THD and the power factor being improved from an unbalanced $43 \%$ to a balanced $25 \%$ and from 0.93 to 0.972 , respectively, revealing again that the active filter prototype is correctly operating with a four-wire load. In addition, the same figure shows that the power quality of the supply currents becomes much more improved when the predictive controller is changed from the Euler to the trapezoidal technique, with the supply current THD and the power factor becoming $15 \%$ and 0.98 , respectively. These experimental current waveforms have again a high-frequency ripple, being $4.2 \mathrm{kHz}$ when the APF is operated with the typical Euler technique and $9.5 \mathrm{kHz}$ with the proposed trapezoidal strategy. In Figure 7(a), the neutral current $i_{N}$ was virtually mitigated after the APF was activated, becoming more reduced when the APF was driven with the trapezoidal controller. This experiment revealed the effectiveness of the 4-wire, P-Q theory used in this work together with the predictive current control switching.

Figure 7(b) shows the experimental supply currents $i_{S R}$, $i_{S S}$, and $i_{S T}$ and the neutral current $i_{N}$ obtained with the front-end, controlled rectifier drive and monophasic resistive load of Figure 5(c) at $0.9 \mathrm{~kW}$. Before the APF is activated, as shown in Figure 7(b), the experimental supply currents are completely unbalanced, distorted, and phase-displaced due to the biphasic connection of the front-end rectifier of the motor drive and the resistive load connection; however, when the APF is on using, firstly, the Euler predictive technique and then the trapezoidal version, the supply currents become again balanced with virtual sinusoidal waveforms, such that their THD was improved from an unbalanced $40 \%$ to a balanced $23 \%$ and $18 \%$ for the Euler and trapezoidal methods, respectively, and the power factor from 0.8 to 0.97 and 0.98 again for the Euler and trapezoidal methods, respectively. In Figure $7(\mathrm{~b})$, the neutral current $i_{N}$ was again virtually mitigated after the APF was activated, becoming almost cancelled when the APF used the trapezoidal controller.

A power analyser was used to measure the supply active power, $P$, the supply apparent power, $S$, the per-phase supply current THD, $I_{R S}$ THD, $I_{S S}$ THD, and $I_{T S}$ THD, and the total power factor during the experiments described above. The 


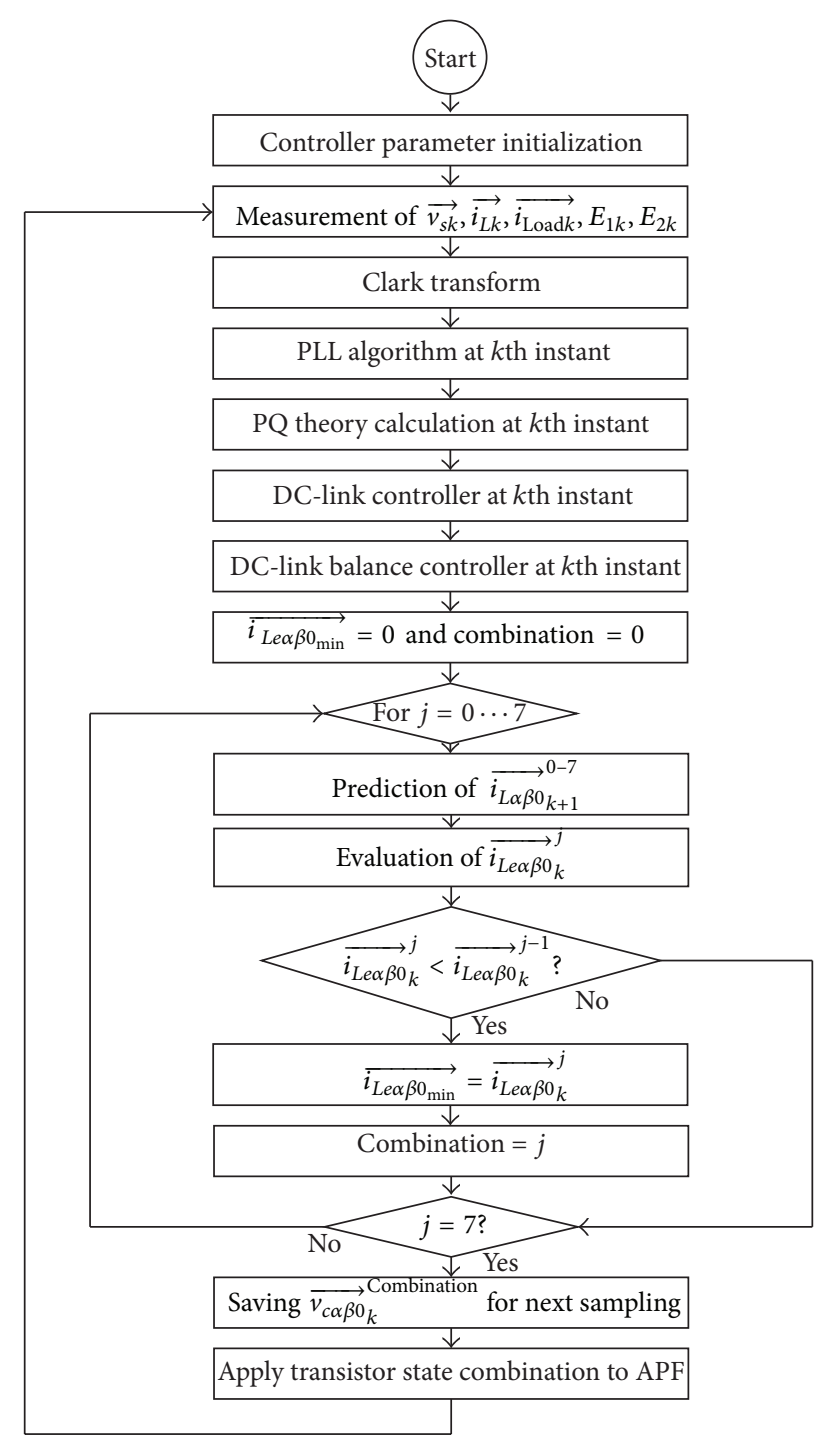

FIGURE 4: Algorithm flow diagram of the predictive current controller.

results are contrasted in the comparative bar plot of Figure 8 calculated with a $2 \mathrm{kVA}$ APF rating, a $127 \mathrm{~V}, 60 \mathrm{~Hz}$ line-toneutral supply voltage, and a $400 \mathrm{~V}$ APF DC link. Figure 8 shows that $P$ slightly rise by approximately $5 \%, 100 \mathrm{~W}$, when the APF prototype was used to improve and balance the supply currents among the experiments; the additional power loss occurring in the transistors, filter inductors and DC-link capacitors of the APF converter due to the high-frequency operation. In comparison with the unbalanced load, the current THD reduction is representative when the APF is used together with the trapezoidal predictive controller to compensate the drawn currents of the balanced load as shown in Figure 8, whereas the current THD is slightly improved when the APF is used together with the Euler strategy and the load cases of Figure 5; nevertheless, the drawn current through the neutral wire is noticeably cancelled when the APF is used to correct the power quality of the four-wire AC loads of Figures 5(b) and 5(c). In contrast with the balanced load, the distribution between apparent and active power for the APF with the unbalanced load becomes equilibrated due to correction of current phase displacement.

Closer inspection of the microprocessor operation revealed that the total period to perform the algorithm of Figure 4 was around $29 \mu$ s with the Euler predictive controller, which is well below the sampling period to ensure minimal delay effects of the control system. Unlike the experimental verification of the Euler predictive controller, the experimental verification of the APF with the trapezoidal predictive controller resulted in a slight increment of algorithm processing time of Figure 4, from $29 \mu \mathrm{s}$ to $30 \mu \mathrm{s}$, which was imperceptible during the experimental verification of the APF.

The presented trapezoidal predictive controller is slightly more complex than the typical predictive strategy to perform the current reference tracking and generates a slight increase of power losses, which could make it inadequate for implementation in low-rated rigs; nevertheless, the ripple current reduction, closer current tracking, and power quality 


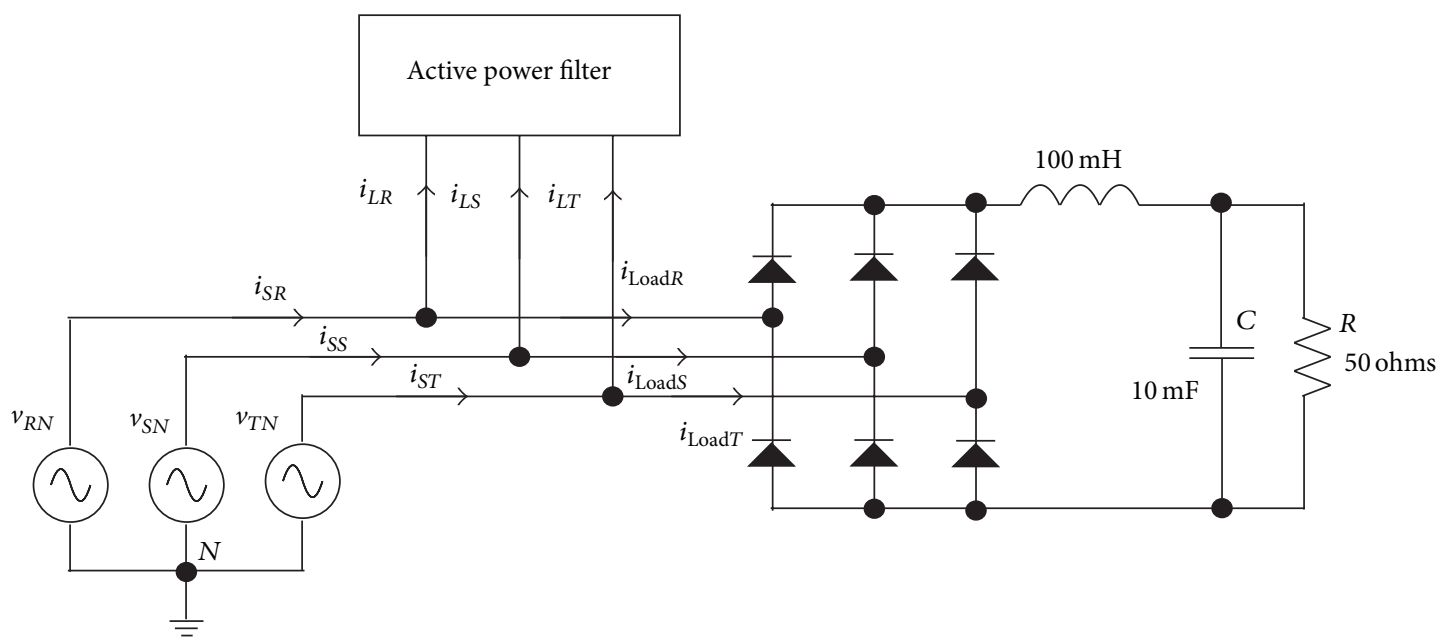

(a)

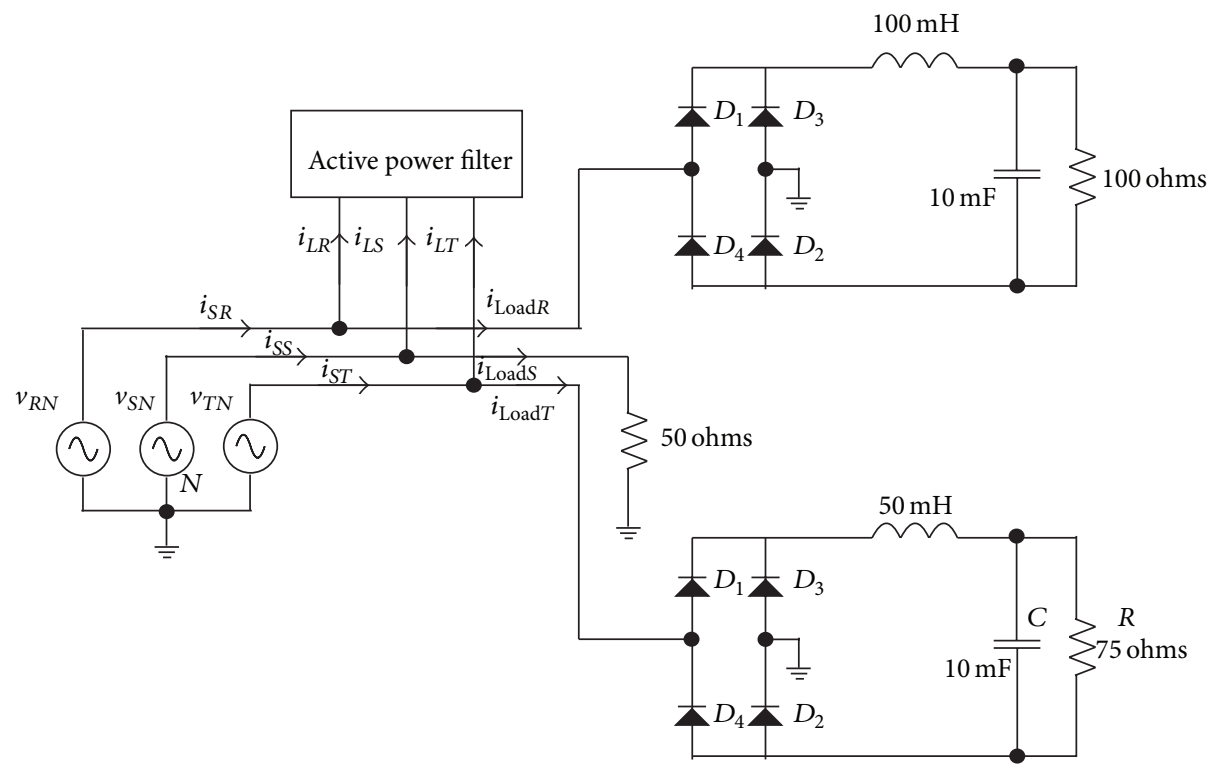

(b)

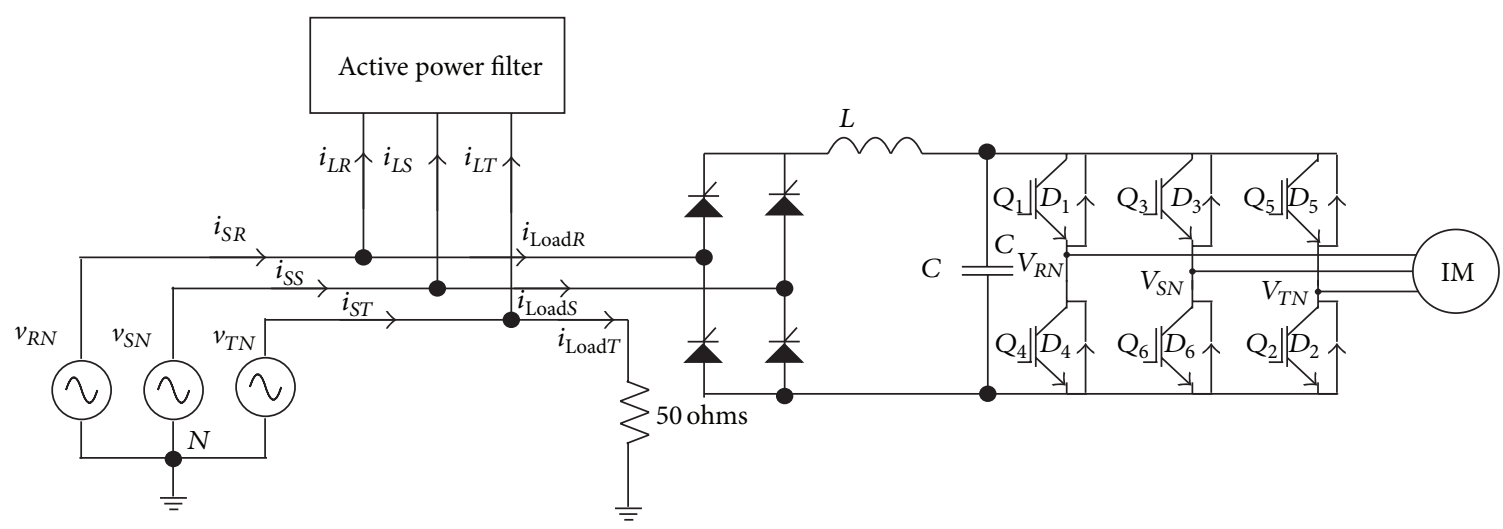

(c)

FIGURE 5: Nonlinear loads used to experimentally verify the APF and predictive current controller of Figure 1. (a) Balanced three-wire load, (b) unbalanced four-wire load, and (c) unbalanced load used at a Metro Power Substation. 


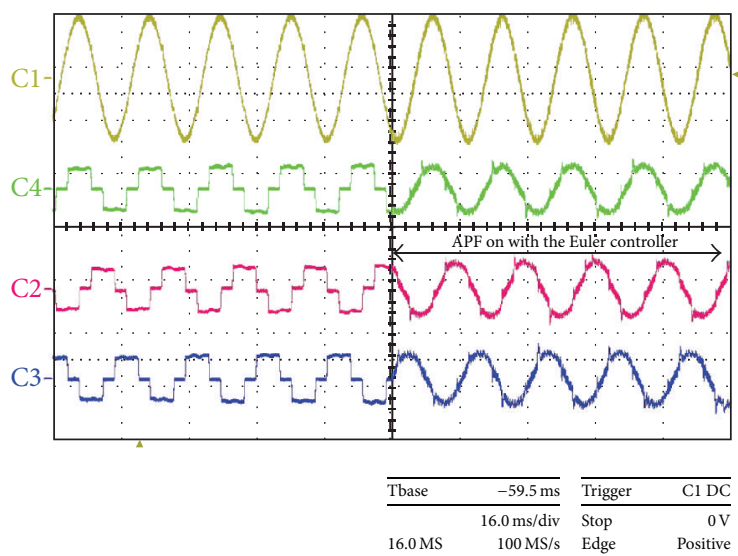

\begin{tabular}{|c|c|c|}
\hline C1 BwL DC1M & $100 \mathrm{~V} / \mathrm{div}$ & $280.0 \mathrm{~V}$ offset \\
\hline C2 DC1M & $10.0 \mathrm{~A} / \mathrm{div}$ & $-11.50 \mathrm{~V}$ offse \\
\hline C3 DC & $10.0 \mathrm{~A} / \mathrm{div}$ & $-28.20 \mathrm{~A}$ offse \\
\hline
\end{tabular}

(a)

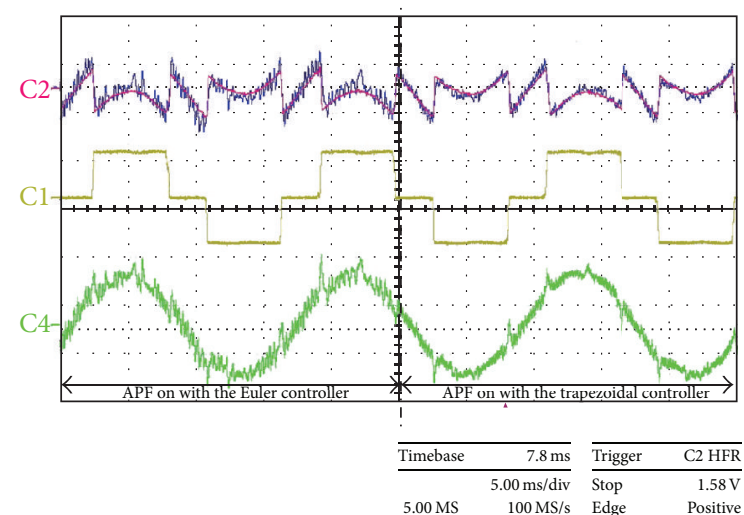

- C1 FBD $5.00 \mathrm{~A} / \mathrm{div} \quad 480 \mathrm{~mA}$ offset

- C2 F B D1 $5.00 \mathrm{~V} / \mathrm{div} 5.080 \mathrm{~V}$ offset

— C3 FB D $5.00 \mathrm{~A} / \mathrm{div} 5.080 \mathrm{~A}$ offset

C C F B D1 $5.00 \mathrm{~A} / \mathrm{div}-4.820 \mathrm{~V}$ offset

(c)

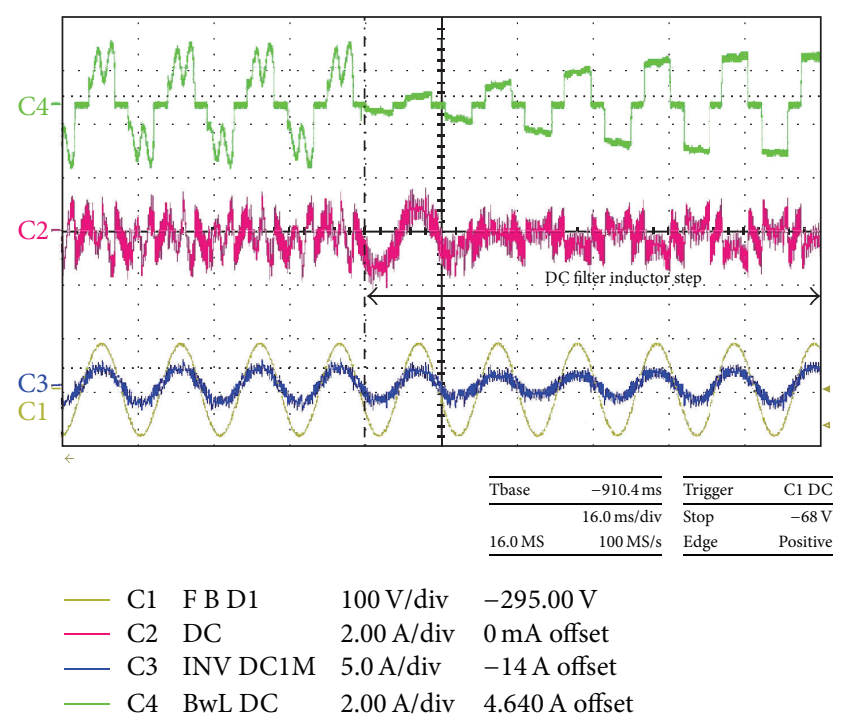

(b)
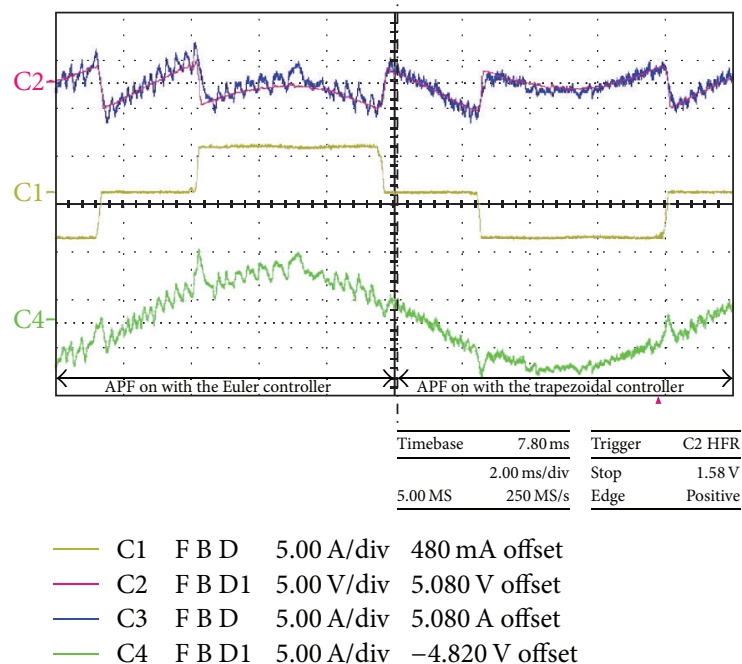

(d)

FIGURE 6: Experimental verification of the APF prototype with the $1.6 \mathrm{~kW}$ balanced load of (a). (a) Measured waveforms $v_{R N}$ (yellow), $i_{S R}$ (green), $i_{S S}$ (red), and $i_{S T}$ (blue) before and after the activation of the APF. (b) Measured response of $v_{R N}$ (yellow), $i_{L R}$ (red), $i_{\text {LoadR }}$ (green), and $i_{S R}$ (yellow) to a filter inductance step from $50 \mathrm{mH}$ to $100 \mathrm{mH}$. (c) Measured response of $i_{L R}$ (blue) and $i_{S R}$ (green) to a predictive current controller step from Euler to the trapezoidal approximation, which is contrasted against the reference $i_{L R}{ }^{*}\left(\right.$ red) and load current $i_{\text {LoadR }}$. $(\mathrm{d})$ Time amplification of (c) at the instant of the predictive controller step. $127 \mathrm{~V}, 60 \mathrm{~Hz}$ supply, $400 \mathrm{~V}$ APF DC link, and a $21.6 \mathrm{kHz}$ APF sampling frequency.

improvement are important advantages to consider over the traditional predictive controller technique. Furthermore, the digital implementation is acceptable for fast microcontrollers, such as a DSPs and hybrid digital controllers, and will be used once the trapezoidal control strategy is implemented to control other power converter systems, which would be suitable to obtain high power quality results.

\section{Conclusions}

The utilization of a trapezoidal predictive technique to generate the filter currents of a four-wire, shunt APF allows the power quality improvement of using unbalanced nonlinear loads for on-land utility applications, such that the supply currents become virtual sinusoidal waves. The latter makes the current control strategy attractive for easy and straight implementation on future power converters that require high-performance power quality; nevertheless, the control technique is suitable for a wide range of power converter applications. In this work, the trapezoidal predictive controller was experimentally verified and evaluated with the four-wire APF under three load conditions; in the first, the load was set up with a three-wire, balanced nonlinear circuit to preliminary check the basic operation of the control 


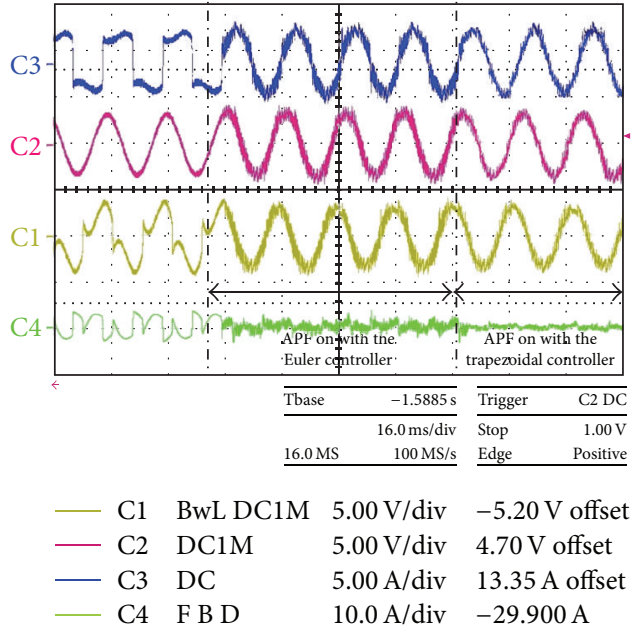

(a)

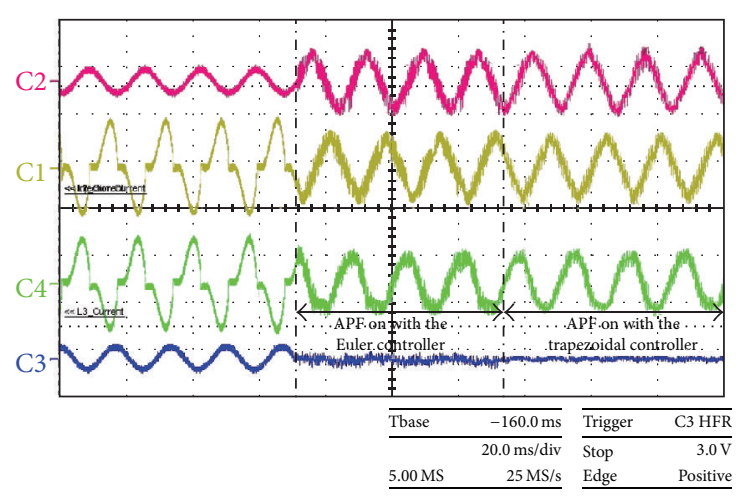

- C1 BwL DC1M $5.00 \mathrm{~V} / \mathrm{div}-5.70 \mathrm{~V}$ offset

- C2 DC1M $\quad 5.00 \mathrm{~V} / \mathrm{div} 14.10 \mathrm{~V}$ offset

- C3 BwL DC1M 10.0 V/div $-32.400 \mathrm{~V}$

- C4 BwL DC $5.00 \mathrm{~A} / \mathrm{div} 4.45 \mathrm{~A}$ offset

(b)

Figure 7: (a) Measured supply current waveforms $i_{S R}$ (blue), $i_{S S}$ (yellow), $i_{S T}$ (red), and $i_{N}$ (green) before and after the activation of the APF with the Euler and Trapezoidal predictive controllers and the load condition of Figure 5(a). (b) Measured supply current waveforms $i_{S R}$ (red), $i_{S S}$ (yellow), $i_{S T}$ (green), and $i_{N}$ (blue) before and after the activation of the APF with the Euler and trapezoidal predictive controllers and the load condition of Figure 5(b). 127 V, $60 \mathrm{~Hz}$ supply, $400 \mathrm{~V}$ APF DC link, and $21.6 \mathrm{kHz}$ APF sampling frequency.

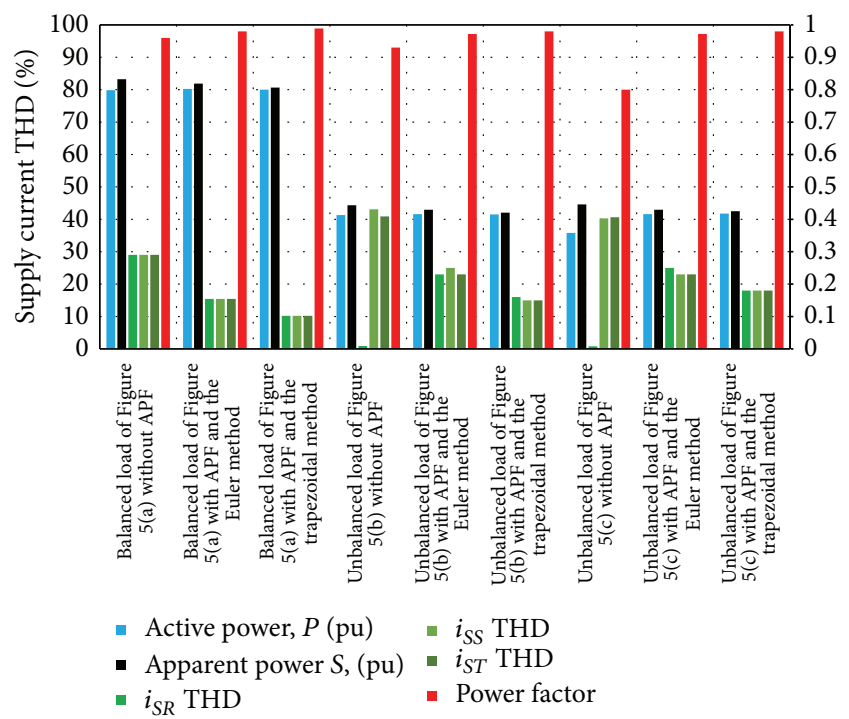

FIGURE 8: Bar plot of the power quality results for the AC load circuits of Figure 5 with the APF prototype operating with the Euler and trapezoidal predictive techniques. $127 \mathrm{~V}, 60 \mathrm{~Hz}$ supply and $2 \mathrm{kVA}$ APF rating.

technique, such that sinusoidal supply current waves were generated and the power quality was improved. A current THD of $10 \%$ and a power factor of 0.989 were measured in the first experiment showing a noticeable improvement in contrast to the traditional predictive technique.

In the second and third load conditions, the load was four-wire, unbalanced nonlinear load, with the load currents being much distorted and producing a neutral current path in both load conditions. The supply current waveforms were all improved and balanced when the APF and the trapezoidal predictive controller were activated, with the neutral current being mitigated; the current THD was $15 \%$ and $18 \%$, respectively, and the power factor was 0.98 in both experiments with a $127 \mathrm{~V}, 60 \mathrm{~Hz}$ three-phase supply voltage. The shape of the supply current waveforms and the power quality were significantly improved in comparison with the original load currents and power quality, with the active power being slightly increased, due to the high-frequency switching losses of the APF power transistors.

The practical realization of the presented trapezoidal predictive controller could consider the use of an extended sampled-data horizon, either forward or backward, to achieve a faster convergence and reduce the current ripple amplitude. This would be convenient for developing power converters with new generation of switching power devices for other applications.

\section{Conflict of Interests}

The authors declare that there is no conflict of interests regarding the publication of this paper.

\section{Acknowledgments}

The authors are grateful to the National Council of Science and Technology (CONACyT), the Instituto Politécnico Nacional (IPN) of Mexico, the Institute of Science and Technology of Mexico City (ICyT), and the Universidad de Talca, Chile, for their encouragement and the realization of the prototype. Additionally, the authors acknowledge the Metropolitan Railway Transportation System of Mexico City (SCT Metro) for the support offered to obtain power quality measurements at Line B installations. 


\section{References}

[1] IEEE Application Guide for IEEE Standard 1547, "IEEE standard for interconnecting distributed resources with electric power systems," IEEE Standard 1547.2-2008, 2008.

[2] S. W. Mohod and M. V. Aware, "A STATCOM-control scheme for grid connected wind energy system for power quality improvement," IEEE Systems Journal, vol. 4, no. 3, pp. 346-352, 2010.

[3] IEEE, "IEEE recommended practices and requirements for harmonic control in electrical power systems," IEEE Standard 519-1992, 1992.

[4] J. D. van Wyk and F. C. Lee, "On a Future for Power Electronics," IEEE Journal of Emerging and Selected Topics in Power Electronics, vol. 1, no. 2, pp. 59-72, 2013.

[5] P. Kanjiya, V. Khadkikar, and H. H. Zeineldin, "Optimal control of shunt active power filter to meet IEEE Std. 519 current harmonic constraints under nonideal supply condition," IEEE Transactions on Industrial Electronics, vol. 62, no. 2, pp. 724734, 2015

[6] P. Acuna, L. Moran, M. Rivera, R. Aguilera, R. Burgos, and V. G. Agelidis, "A single-objective predictive control method for a multivariable single-phase three-level NPC converter-based active power filter," IEEE Transactions on Industrial Electronics, vol. 62, no. 7, pp. 4598-4607, 2015.

[7] P. Acuna, L. Moran, M. Rivera, R. Aguilera, R. Burgos, and V. G. Agelidis, "A single-objective predictive control method for a multivariable single-phase three-level NPC converter-based active power filter," IEEE Transactions on Industrial Electronics, vol. 62, no. 7, pp. 4598-4607, 2015.

[8] P. Jintakosonwit, H. Fujita, and H. Akagi, "Control and performance of a fully-digital-controlled shunt active filter for installation on a power distribution system," IEEE Transactions on Power Electronics, vol. 17, no. 1, pp. 132-140, 2002.

[9] Z. Xiao, X. Deng, R. Yuan, P. Guo, and Q. Chen, "Shunt active power filter with enhanced dynamic performance using novel control strategy," IET Power Electronics, vol. 7, no. 12, pp. 31693181, 2014.

[10] P. Acuna, L. Moran, M. Rivera, J. Rodriguez, and J. Dixon, "Improved active power filter performance for distribution systems with renewable generation," in Proceedings of the 38th Annual Conference on IEEE Industrial Electronics Society (IECON '12), pp. 1344-1349, Montreal, Canada, October 2012.

[11] P. Acuna, L. Moran, M. Rivera, J. Dixon, and J. Rodriguez, "Improved active power filter performance for renewable power generation systems," IEEE Transactions on Power Electronics, vol. 29, no. 2, pp. 687-694, 2014.

[12] H. Akagi, E. H. Watanabe, and M. Aredes, Instantaneous Power Theory and Applications to Power Conditioning, IEEE Press Series on Power Engineering, Wiley-IEEE Press, 2007.

[13] R. P. Aguilera and D. E. Quevedo, "Predictive control of power converters: designs with guaranteed performance," IEEE Transactions on Industrial Informatics, vol. 11, no. 1, pp. 53-63, 2015.

[14] P. Cortés, J. Rodríguez, P. Antoniewicz, and M. Kazmierkowski, "Direct power control of an AFE using predictive control," IEEE Transactions on Power Electronics, vol. 23, no. 5, pp. 2516-2523, 2008.

[15] J. Scoltock, T. Geyer, and U. K. Madawala, "Model predictive direct power control for grid-connected NPC converters," IEEE Transactions on Industrial Electronics, vol. 9, no. 62, pp. 53195328, 2015.
[16] M. Lopez, J. Rodriguez, C. Silva, and M. Rivera, "Predictive torque control of a multidrive system fed by a dual indirect matrix converter," IEEE Transactions on Industrial Electronics, vol. 62, no. 5, pp. 2731-2741, 2015.

[17] A. Bhattacharya and C. Chakraborty, "A shunt active power filter with enhanced performance using ANN-based predictive and adaptive controllers," IEEE Transactions on Industrial Electronics, vol. 58, no. 2, pp. 421-428, 2011.

[18] R. Vargas, U. Ammann, B. Hudoffsky, J. Rodriguez, and P. Wheeler, "Predictive torque control of an induction machine fed by a matrix converter with reactive input power control," IEEE Transactions on Power Electronics, vol. 25, no. 6, pp. 1426$1438,2010$.

[19] B. S. Riar, T. Geyer, and U. K. Madawala, "Model predictive direct current control of modular multilevel converters: modeling, analysis, and experimental evaluation," IEEE Transactions on Power Electronics, vol. 30, no. 1, pp. 431-439, 2015.

[20] L. Tarisciotti, P. Zanchetta, A. Watson, J. C. Clare, M. Degano, and S. Bifaretti, "Modulated model predictive control for a three-phase active rectifier," IEEE Transactions on Industry Applications, vol. 51, no. 2, pp. 1610-1620, 2015.

[21] A. Luo, X. Xu, L. Fang, H. Fang, J. Wu, and C. Wu, "Feedbackfeedforward PI-type iterative learning control strategy for hybrid active power filter with injection circuit," IEEE Transactions on Industrial Electronics, vol. 57, no. 11, pp. 3767-3779, 2010.

[22] Y. F. Wang and Y. W. Li, “Three-phase cascaded delayed signal cancellation PLL for fast selective harmonic detection," IEEE Transactions on Industrial Electronics, vol. 60, no. 4, pp. 14521463, 2013.

[23] M. Rivera, C. Rojas, J. Rodríguez, P. Wheeler, B. Wu, and J. Espinoza, "Predictive current control with input filter resonance mitigation for a direct matrix converter," IEEE Transactions on Power Electronics, vol. 26, no. 10, pp. 2794-2803, 2011. 


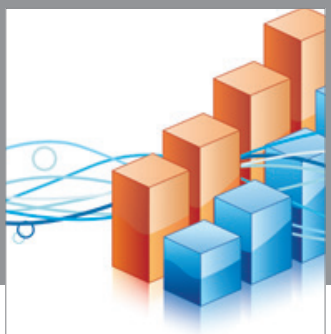

Advances in

Operations Research

vatem alat4

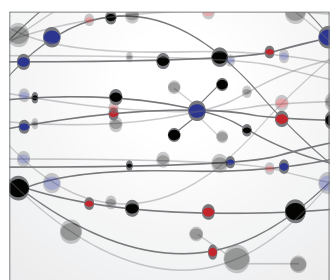

\section{The Scientific} World Journal
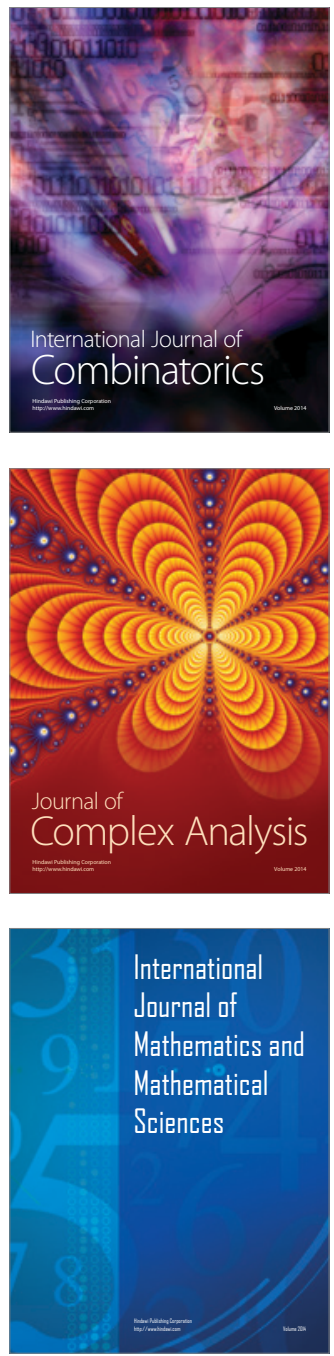
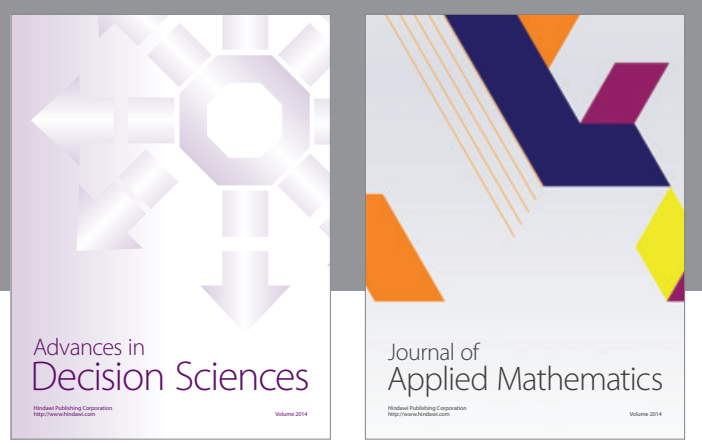

Algebra

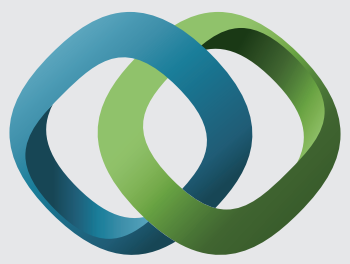

\section{Hindawi}

Submit your manuscripts at

http://www.hindawi.com
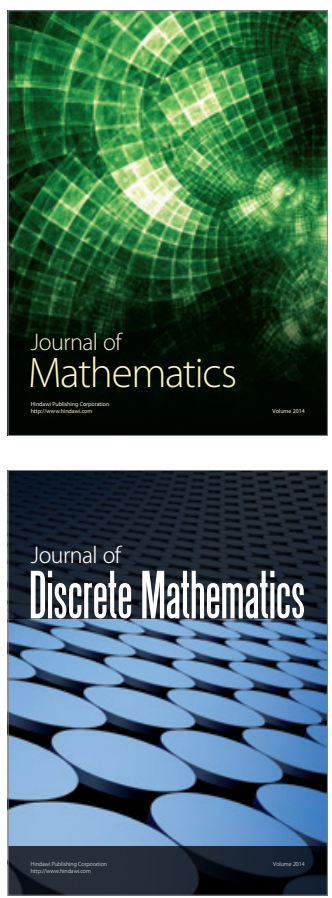

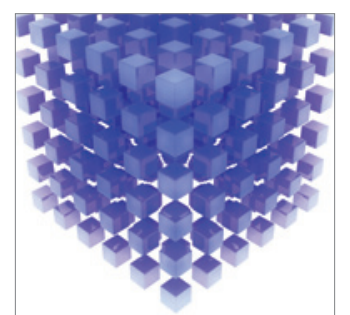

Mathematical Problems in Engineering
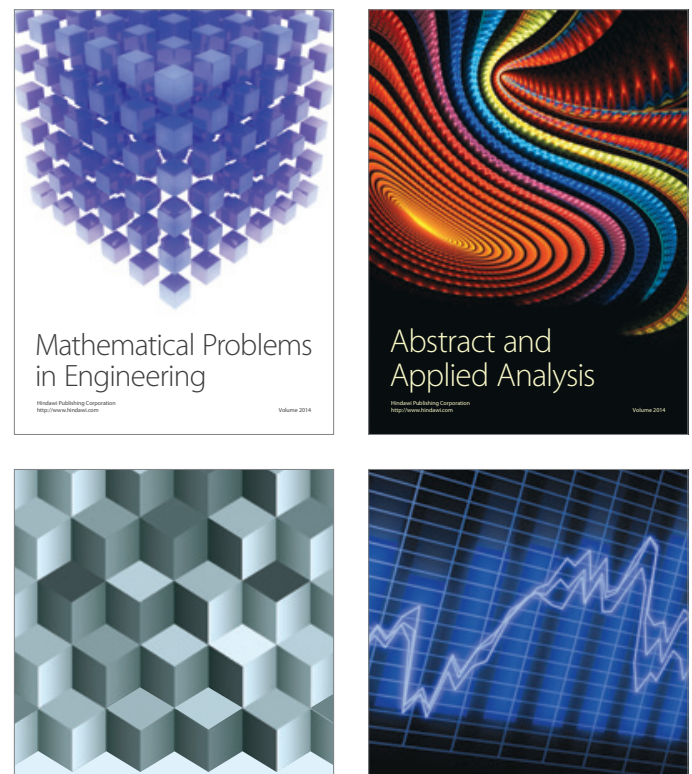

Journal of

Function Spaces

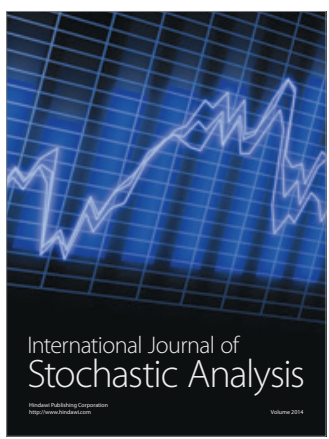

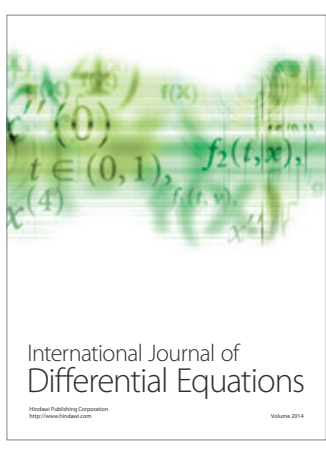
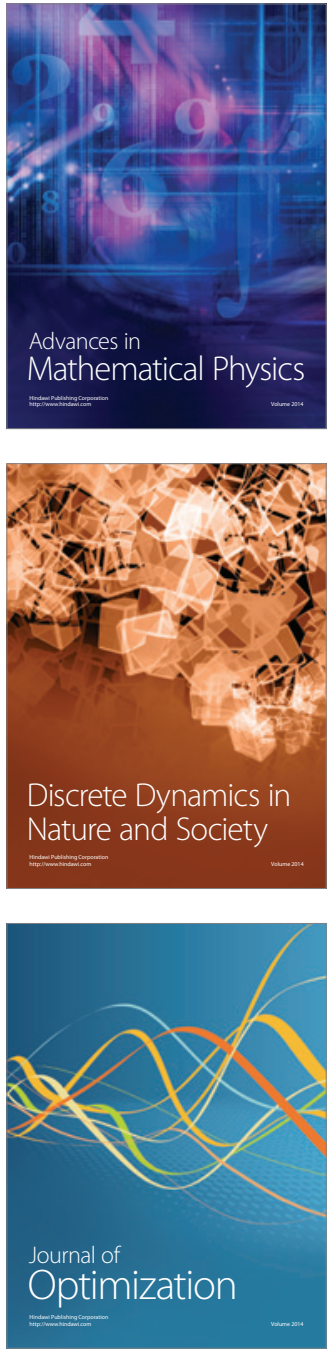